\title{
Modeling of Recognition Degree of Refuge Areas by Kyoto City Residents in Post-Earthquake Fire Event
}

\author{
TOMOAKI NISHINO, KEISUKE HIMOTO, and TAKEYOSHI TANAKA \\ Disaster Prevention Research Institute \\ Kyoto University \\ Gokasho, Uji, Kyoto 611-0011, Japan
}

\begin{abstract}
In this study, a model for recognition degree of refuge areas by Kyoto City residents in post-earthquake fire event was developed based on the data obtained by an interview survey. When a large earthquake hits a city in Japan, a tremendous number of evacuees may wander around in urban area escaping from hazards due to conflagrations following the earthquake. We have been developing a simulation model for city evacuation of residents in post-earthquake fire as a tool to evaluate effectiveness of evacuation safety measures. For the further refinement, it is important to accurately estimate evacuation destination of residents considering bias of recognition degree of refuge areas. The interview survey was carried out at 104 spots on busy streets in Kyoto City and replies from 2,267 residents were collected from 1 September 2009 to 30 November 2009. In the interview, the names of open-spaces recognized as evacuation destination were asked having the subjects imagine that conflagrations had taken place in urban area. The governing factors of recognition degree of refuge areas were identified and evacuation destination of residents was formulated by adopting a probabilistic model.
\end{abstract}

KEYWORDS: evacuation, interview survey, refuge area, post-earthquake fire, Kyoto City.

\section{NOMENCLATURE LISTING}

$\begin{array}{llll}d & \text { dummy variable } & s & \text { distance }(\mathrm{m}) \\ F & \text { cumulative distribution function } & t & \text { duration of residence (year) } \\ L & \text { likelihood function } & X & \text { random variable } \\ M & \text { number of interviewed residents } & \text { Greek } & \\ N & \text { number of refuge areas } & \alpha & \text { constant } \\ P & \text { probability } & \beta & \text { constant } \\ R & \text { correlation coefficient } & \Phi & \text { potential } \\ S & \text { area (ha) } & \Theta & \text { threshold }\end{array}$

\section{INTRODUCTION}

When a large earthquake hits a city in Japan, a tremendous number of evacuees may wander around in urban area escaping from spread of fire following the earthquake, which often involves thousands of buildings. For ensuring residents' safety from the fires, it is essential to implement effective evacuation safety measures in advance. As one of the measures, existing open-spaces in urban area have been designated by local government of Japan as the refuge areas against conflagrations following a major earthquake. For validating the effectiveness of such measure, i.e., whether the refuge areas are able to accommodate all of the potential evacuees, it is important to predict a big picture of city evacuation in expected post-earthquake fire scenarios.

We have been developing an agent-based model for city evacuation of residents in post-earthquake fire. The model has been validated by reconstructing the evacuation in the Kanto Earthquake Fire in 1923, where the spatial distribution of fatalities calculated by the model was similar to the survey report [1-2]. It is reported that evacuees selected well-known spacious parks as their destination among several options at that time; for example as many as 400,000 evacuees gathered at Imperial Palace Park in Tokyo City. However in the simulation, such difference in the recognition level among the refuge areas was not considered, i.e., residents recognized all of the refuge areas as the potential destination. In order to predict the evacuation behavior more reasonably, it is essential to incorporate effect by bias of recognition degree of refuge areas. 
Several researches regarding evacuation destination of residents in post-earthquake fire have been carried out. They are classified into two groups in terms of research methodology: (1) analysis of the existing data regarding the past evacuation case [3]; and (2) questionnaire survey on residents' attitude [4]. The advantage of these researches is to provide the basic data regarding the evacuation destination of residents in the target area. However, there is a difficulty that decision structure of evacuation destination due to recognition degree of refuge areas is not discussed and the data is not available for the simulation by the present model. Thus, it is essential to develop a method which can predict evacuation destination of a resident considering recognition degree of refuge areas.

In this study, a model for recognition degree of refuge areas by Kyoto City residents in post-earthquake fire event was developed based on the data obtained by an interview survey. In this paper, the survey data was analyzed to identify the governing factors of recognition degree of refuge areas. Then the recognition degree was formulated considering the factors and validated by using the survey data.

\section{INTERVIEW SURVEY TO KYOTO CITY RESIDENTS}

The refuge areas against conflagrations designated by local government of Kyoto are listed in Table 1, whose locations are indicated by box symbols in Fig. 1 [5]. Note that the capacity of the refuge area is calculated by dividing available area for evacuation by the area required by one evacuee which is assumed to be $2.0 \mathrm{~m}^{2}$. The number of the refuge areas in Kyoto City is 67 and all of them ensure more than 1 ha area available for safe evacuation from radiant heat from fires. Several historical open-spaces, such as Imperial Palace Park of Kyoto, Nijo Castle, Kinkakuji Temple and Ninnaji Temple, are also included among the designated refuge areas. One of the features of their locations is that many of them are located along the rivers and skirts of mountain and few of them are inside densely-built area.

\section{Outline of Survey}

The outline of the interview survey is shown in Table 2. The survey was carried out on the streets of Kyoto City in the daytime from 1 September 2009 to 30 November 2009. The number of the spots where the interview was conducted was 104, whose locations are indicated by circle symbols in Fig. 1. The interview spots were allocated on busy intersections at roughly $500 \mathrm{~m}$ intervals in the area bounded by Higasiyama

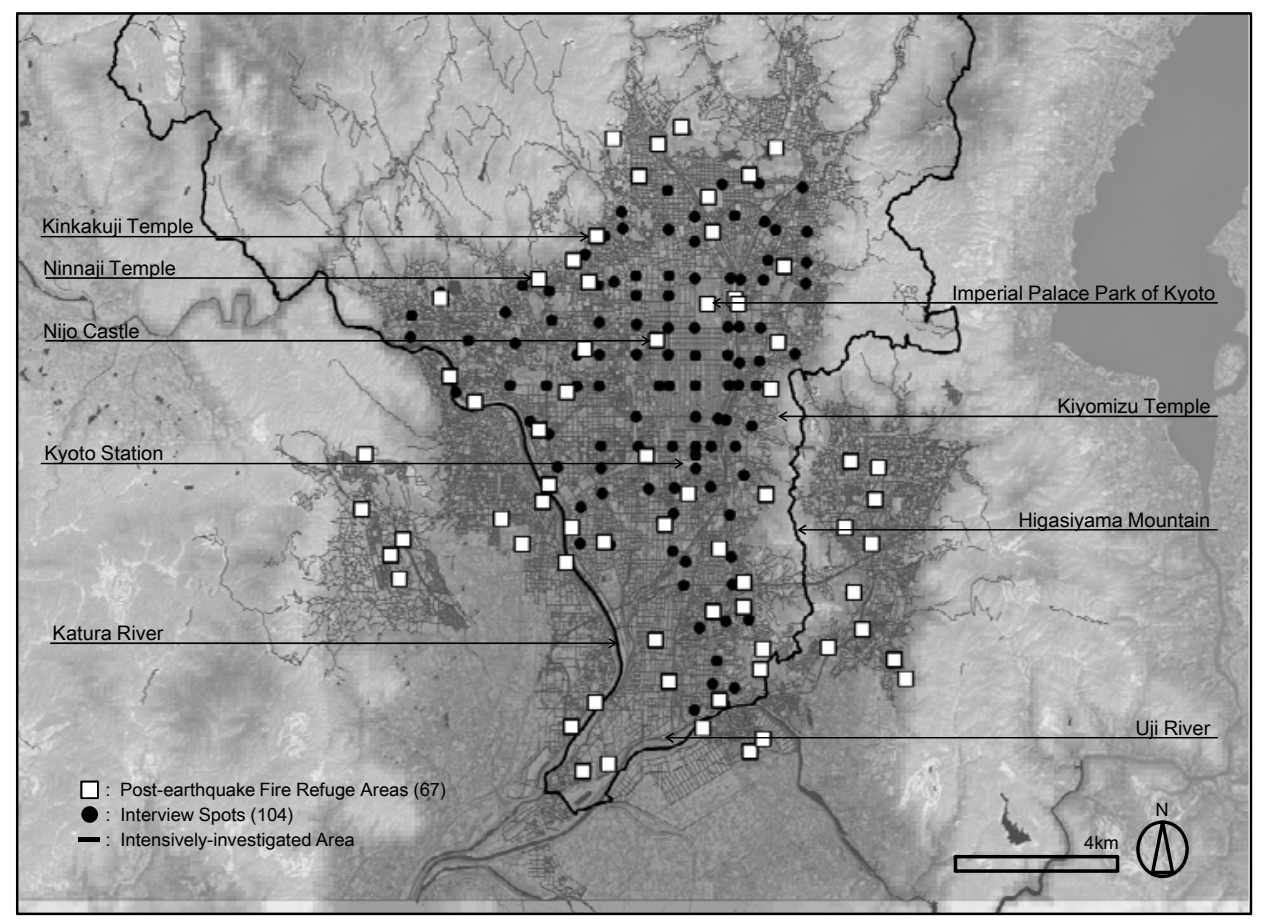

Fig. 1. Locations of refuge areas designated by local government of Kyoto. 
Table 1. List of refuge areas designated by local government of Kyoto.

\begin{tabular}{|c|c|c|c|c|c|}
\hline ID & Region & Name of post-earthquake fire refuge area & Class & $\begin{array}{l}\text { Site } \\
\text { (ha) }\end{array}$ & $\begin{array}{c}\text { Available } \\
\text { (ha) }\end{array}$ \\
\hline 1 & \multirow{6}{*}{ Kita } & Golf course of Kyoto-Nisikamo & other & 40.0 & 39.0 \\
\hline 2 & & Omiya traffic park & park & 2.0 & 1.2 \\
\hline 3 & & Kinkakuji temple & historical & 17.5 & 1.0 \\
\hline 4 & & Ritumeikan university ground & school & 10.0 & 1.8 \\
\hline 5 & & Rakusei high school ground & school & 1.5 & 1.5 \\
\hline 6 & & Golf cource of Kyoto-Kamigamo & other & 55.6 & 39.0 \\
\hline 7 & Kamigyo & Imperial palace park of Kyoto & historical & 87.0 & 34.7 \\
\hline 8 & \multirow{5}{*}{ Sakyo } & Kyoto botanical garden & other & 31.2 & 28.0 \\
\hline 9 & & Takaragaike park & park & 30.0 & 14.0 \\
\hline 10 & & Kyoto university ground & school & 11.8 & 4.3 \\
\hline 11 & & Okazaki park & park & 4.5 & 4.5 \\
\hline 12 & & Takaragaike sports space & park & 7.0 & 5.6 \\
\hline 13 & \multirow{2}{*}{ Nakagyo } & Nijo castle & historical & 21.8 & 7.0 \\
\hline 14 & & Shimadzu corporation ground & other & 20.5 & 2.8 \\
\hline 15 & Higasiyama & Hiyosigaoka high school ground & school & 12.5 & 4.7 \\
\hline 16 & Simogyo & Umekoji park & park & 22.7 & 10.0 \\
\hline 17 & \multirow{6}{*}{ Minami } & Tonoda park & park & 3.5 & 1.7 \\
\hline 18 & & Kamitoba park & park & 1.7 & 1.7 \\
\hline 19 & & Kisyoin park & park & 9.9 & 7.8 \\
\hline 20 & & Tonan high school ground & school & 1.4 & 1.0 \\
\hline 21 & & Katura garrison & other & 37.4 & 1.0 \\
\hline 22 & & Kuzebasi western park & park & 3.1 & 3.1 \\
\hline 23 & \multirow{4}{*}{ Ukyo } & Ninnaji temple & historical & 14.0 & 1.3 \\
\hline 24 & & Nisikyogoku athletic park & park & 15.0 & 7.2 \\
\hline 25 & & Saiin park & park & 2.6 & 2.3 \\
\hline 26 & & Bukkyo university ground & school & 18.0 & 18.0 \\
\hline 27 & \multirow{20}{*}{ Husimi } & Kyoto police school ground & school & 12.4 & 3.0 \\
\hline 28 & & Fire academy ground & school & 11.3 & 5.4 \\
\hline 29 & & Kyoto university of education & school & 11.0 & 5.3 \\
\hline 30 & & Momoyama imperial mausoleum & other & 76.0 & 21.7 \\
\hline 31 & & Husimi park & park & 2.0 & 1.9 \\
\hline 32 & & Simotoba park & park & 2.0 & 1.9 \\
\hline 33 & & Misu park & park & 2.2 & 2.2 \\
\hline 34 & & Ogurisu junior high school ground & school & 3.5 & 1.3 \\
\hline 35 & & Rituryo junior high school ground & school & 3.2 & 1.1 \\
\hline 36 & & Kasugaoka junior high school ground & school & 3.2 & 1.3 \\
\hline 37 & & Hino outdoor center & other & 1.6 & 1.6 \\
\hline 38 & & Mukaijima-south elementary school ground & school & 8.7 & 5.6 \\
\hline 39 & & Mukaijima junior high school ground & school & 7.0 & 2.1 \\
\hline 40 & & Mukaijima-Hujinoki elementary school ground & school & 5.0 & 4.9 \\
\hline 41 & & Husimi-Kitahori park & park & 5.4 & 3.7 \\
\hline 42 & & Hadukasi athletic park & park & 10.4 & 2.8 \\
\hline 43 & & Kyoto driving license examination ground & other & 8.9 & 5.5 \\
\hline 44 & & Yokooji athletic park & park & 13.0 & 12.8 \\
\hline 45 & & Kyoto racetrack & other & 18.0 & 12.1 \\
\hline 46 & & Hukakusa junior high school ground & school & 9.9 & 1.5 \\
\hline 47 & \multirow{4}{*}{ Yamasina } & Yamasina central park & park & 4.0 & 2.0 \\
\hline 48 & & Higasiyama high school ground & school & 3.0 & 1.3 \\
\hline 49 & & Higasino park & park & 6.3 & 3.9 \\
\hline 50 & & Rakuto driving school & other & 1.7 & 1.6 \\
\hline
\end{tabular}


Table 1 (continued). List of refuge areas designated by local government of Kyoto.

\begin{tabular}{|c|c|c|c|c|c|}
\hline ID & Region & Name of post-earthquake fire refuge area & Class & $\begin{array}{l}\text { Site } \\
\text { (ha) }\end{array}$ & $\begin{array}{c}\text { Available } \\
\text { (ha) }\end{array}$ \\
\hline 51 & \multirow{2}{*}{ Yamasina } & Ryukoku university ground & school & 6.0 & 5.4 \\
\hline 52 & & Kansyuji park & park & 4.4 & 3.8 \\
\hline 53 & \multirow{7}{*}{ Nisikyo } & Katura high school ground & school & 5.4 & 1.8 \\
\hline 54 & & Katuragawa junior high school ground & school & 4.8 & 2.4 \\
\hline 55 & & Obatagawa central park & park & 9.0 & 9.0 \\
\hline 56 & & Rakusei junior high school ground & school & 6.0 & 2.6 \\
\hline 57 & & Takenosato elementary school ground & school & 7.3 & 2.2 \\
\hline 58 & & Katurasaka elementary school ground & school & 5.9 & 5.8 \\
\hline 59 & & Kyoto city university of arts & school & 7.2 & 3.4 \\
\hline 60 & - & Right-bank of Kamo river (upper part) & river & 2.3 & 2.3 \\
\hline 61 & - & Right-bank of Kamo river (middle part) & river & 5.6 & 4.0 \\
\hline 62 & - & Right-bank of Kamo river (lower part) & river & 3.1 & 3.1 \\
\hline 63 & - & Left-bank of Kamo river (lower part) & river & 3.2 & 2.7 \\
\hline 64 & - & Maruyama park & park & 13.0 & 7.9 \\
\hline 65 & - & Left-bank of Katura river (lower part) & river & 8.0 & 8.0 \\
\hline 66 & - & Left-bank of Katura river (middle part) & river & 7.0 & 6.3 \\
\hline 67 & - & Right-bank of Katura river (upper part) & river & 15.5 & 13.7 \\
\hline
\end{tabular}

Table 2. Outline of interview survey.

\begin{tabular}{|l|c|c|c|c|}
\hline Investigation style & \multicolumn{4}{|c|}{ Interview } \\
\hline Investigation period & \multicolumn{4}{|c|}{ Sep. $1^{\text {st }}, 2009-$ Nov. $30^{\text {th }}, 2009$ (daytime) } \\
\hline Number of interview spot & \multicolumn{4}{|c|}{104 (on the streets) } \\
\hline Number of subjects & 2,939 (residents $: 2,267$ tourists : 271 other : 401) \\
\hline \multirow{4}{*}{$\begin{array}{l}\text { Breakdown of residents } \\
\text { (age and sex) }\end{array}$} & Age & Male & Female & Total \\
\cline { 2 - 5 } & $18-25$ & 198 & 201 & 399 \\
\cline { 2 - 5 } & $26-35$ & 159 & 172 & 331 \\
\cline { 2 - 5 } & $36-45$ & 133 & 164 & 297 \\
\cline { 2 - 5 } & $46-55$ & 110 & 141 & 251 \\
\cline { 2 - 5 } & $56-65$ & 186 & 185 & 371 \\
\cline { 2 - 5 } & $66-$ & 302 & 316 & 618 \\
\hline Number of subjects at each spot & \multicolumn{4}{|c}{$10-33:[$ male, female] and [young, middle, old] } \\
\hline
\end{tabular}

Mountain, Uji River and Katura River. At each interview spot, pedestrians were classified into 6 categories except foreigners and people under 18: [male, female] and [young-age, middle-age, old-age], and 5 subjects at each category were selected for avoiding the bias of sex and age. As a result, the number of the interviewed residents was 2,276. The breakdown of the interviewed residents is shown in Table 2, where proportion of old residents over 65 was relatively large. The number of the interviewed residents at each interview spot was in the range from 10 to 33, and the mean value was 21.8. Especially near the tourist site and business district, majority of the subjects were visitors for sightseeing and business, so that the interviewed residents were few.

\section{Details of Interview}

The flow of the interview is shown in Fig. 2 with the orally-asked questions. The questions to the subjects consist of two parts: (a) question on evacuation destination; and (b) question on attributes of the subject. The procedure of the interview is described as follows:

1. Two pictures of the conflagration scenes in Kobe Earthquake in 1995 were shown to the subject in order to make all the subjects share common image for the fire. Then we requested the subject to 
imagine the situation that conflagrations had taken place in urban area and buildings around the interview spot were burning.

2. Assuming that the subject had to evacuate from the interview spot to a refuge area in urban area, the name or location of the destination was asked to the subject without showing any information about the refuge areas. In addition, the following questions were asked: (a) the time required to reach the destination on foot from the spot; (b) the direction of the destination from the spot; and (c) the reason of the choice.

3. The above question was repeated until the subject answered 5 destinations at a maximum. Then, the attributes of the subject such as the sex, age and duration of residence in Kyoto City were asked to complete the interview.

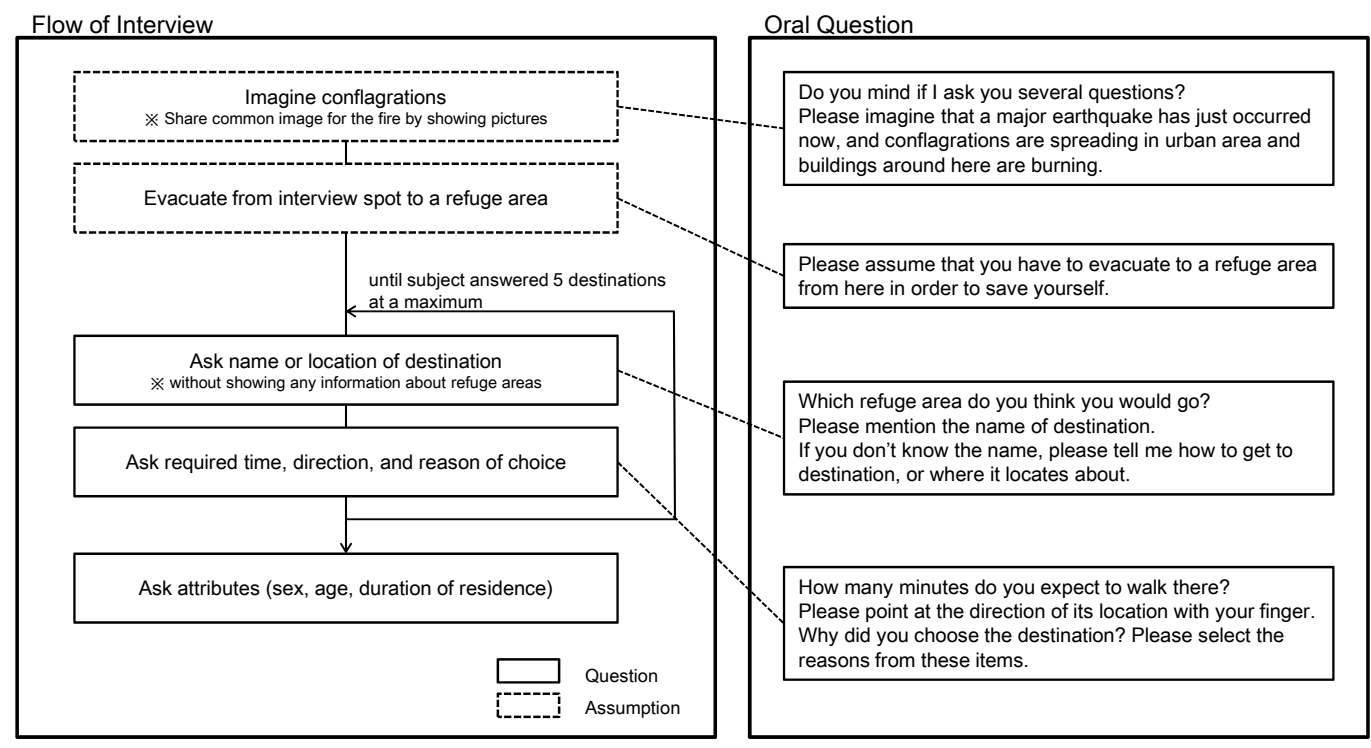

Fig. 2. Flow of interview and orally-asked questions.

\section{Results and Discussion}

The answers obtained by the interview survey were analyzed and the factors governing the recognition degree were identified. If the required time or the direction answered by a subject had large error even though he answered the name of the refuge area correctly, it was deemed that the subject did not recognize the refuge area correctly.

\section{Contribution Degree by Duration of Residence}

The subjects were classified in terms of duration of residence as shown in Table 3, where duration of residence was categorized into Six levels: (a) within 1 year; (b) within 1 to 5 years; (c) within 5 to 10 years; (d) within 10 to 20 years; (e) within 20 to 40 years; and (f) within more than 40 years. The value in parenthesis in Table 3 corresponds to the proportion to the total number at each level (rightmost column). The number of the subjects who could not answer any refuge areas correctly was 1,209, which amounts to $53 \%$ of the total number of the subjects. On the other hand, the number of the subjects who could answer at least one refuge area correctly was 1,058 . However, note that most of the subjects could recognize only one refuge area. The proportion of the subjects who could not answer any refuge areas correctly was the highest at the levels (a) within 1 year and (b) within 1 to 5 years. The proportion decreased with increase in duration of residence, though the influence of duration of residence was not remarkable. 
Table 3. Breakdown of subjects according to duration of residence.

\begin{tabular}{|c|c|c|c|c|c|c|}
\hline Duration of & \multicolumn{5}{|c|}{ Number of recognized refuge areas } & \multirow{2}{*}{ Total } \\
\cline { 2 - 6 } residence & $\mathbf{0}$ & $\mathbf{1}$ & $\mathbf{2}$ & $\mathbf{3}$ & $\mathbf{4}-$ & \\
\hline-1 year & $123(0.62)$ & $61(0.31)$ & $13(0.07)$ & $0(0.00)$ & $0(0.00)$ & $197(1.00)$ \\
\hline $1-5$ years & $248(0.63)$ & $122(0.31)$ & $17(0.04)$ & $6(0.02)$ & $1(0.00)$ & $394(1.00)$ \\
\hline 5-10 years & $116(0.54)$ & $77(0.36)$ & $20(0.09)$ & $2(0.01)$ & $0(0.00)$ & $215(1.00)$ \\
\hline $10-20$ years & $149(0.56)$ & $99(0.37)$ & $16(0.06)$ & $2(0.01)$ & $0(0.00)$ & $266(1.00)$ \\
\hline $20-40$ years & $258(0.51)$ & $210(0.41)$ & $40(0.08)$ & $1(0.00)$ & $0(0.00)$ & $509(1.00)$ \\
\hline 40 years- & $315(0.46)$ & $290(0.42)$ & $68(0.10)$ & $13(0.02)$ & $0(0.00)$ & $686(1.00)$ \\
\hline total & $1,209(0.53)$ & $859(0.38)$ & $174(0.08)$ & $24(0.01)$ & $1(0.00)$ & $2267(1.00)$ \\
\hline
\end{tabular}

\section{Asymmetry of Recognition Sphere}

The top 10 refuge areas which obtained the most answers are shown in Fig. 3. Imperial Palace Park of Kyoto was the most, followed by Nijo Castle, Umekoji Park and Kyoto University Ground. All the top 10 refuge areas are located in the area bounded by Higasiyama Mountain, Uji River and Katura River. Among the refuge areas, Imperial Palace Park of Kyoto was selected as study refuge area and recognition sphere of it was analyzed.

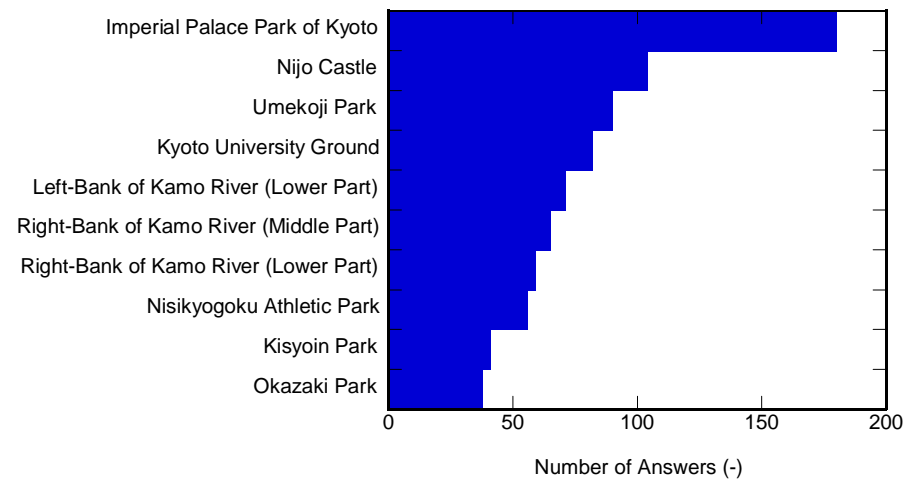

Fig. 3. Top 10 refuge areas of number of answers.

The proportion of the subjects who named Imperial Palace Park of Kyoto at each interview spot is shown in Fig. 4, where the size of the circles corresponds to the proportion. The proportion was higher as an interview spot is closer to Imperial Palace Park of Kyoto. The proportion basically decreased with increase in distance even though the values varied depending on direction. In Fig. 4, the proportion at the interview spots along Marutamati St. (dotted line A) and Imadegawa St. (dotted line B) are also illustrated by linegraphs, which run east-to-west tangent to southern and northern edge of Imperial Palace Park of Kyoto. Focusing on the interview spots along Marutamati St. and Imadegawa St., the subjects who named Imperial Palace Park of Kyoto were concentrated on the west side of Kamo River which runs north-to-south between Kawaramati St. and Kawabata St., and decreased suddenly at the spots across the river to the east. It is conceivable that geographical gap, such as river which lies between a refuge area and a resident, induces some psychological resistance and affect the choice of the refuge area. Almost all of the subjects who named Imperial Palace Park of Kyoto were distributed in the area within $2 \mathrm{~km}$ from the refuge area. However there were a small number of exceptions which still named despite of larger distance to the refuge area. The contributing factors of this are as follows: (1) Imperial Palace Park of Kyoto is included in the range of living activities of the subjects; and (2) recognition sphere of Imperial Palace Park of Kyoto as evacuation destination is much broad. 




Fig. 4. Spatial distribution of subjects who named Imperial Palace Park of Kyoto.

\section{MODEL FOR RECOGNITION DEGREE OF REFUGE AREAS BY RESIDENTS}

The schematic of the recognition model of refuge areas by Kyoto City residents is shown in Fig. 5. In the model, the probability that a refuge area is recognized as evacuation destination by a resident in postearthquake fire situation $P_{R}$ (the recognition probability) is defined.

\section{Recognition Probability}

Formulating the recognition probability $P_{R}$, the following hypothetical quantities were assumed: (A) potential of a refuge area $\Phi$; and (B) threshold of a resident $\Theta$. As the potential of a refuge area $\Phi$ exceeds the threshold of a resident $\Theta$, the refuge area is assumed to be recognized as evacuation destination by the resident:

$\Phi \geq \Theta$

where the potential $\Phi$ and the threshold $\Theta$ are the random variables. The potential $\Phi$ corresponds to the hypothetical value for mathematically formulating the decision structure of evacuation destination, and the larger the value of the potential $\Phi$, the easier the refuge area is recognized. In the model, the potential $\Phi$ is assumed to be the specific value of each refuge area and is expressed as follows:

$\Phi_{j}=\bar{\Phi}_{j}+\Phi_{j}^{\prime}$ 


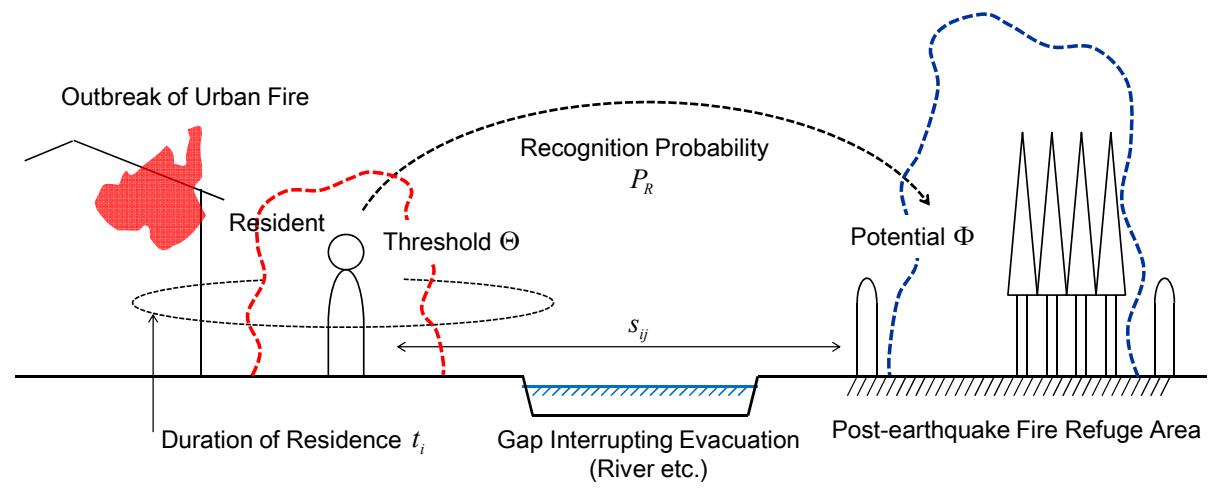

Fig. 5. Schematic of recognition model of refuge areas by residents.

where $j$ is the identification mark of a refuge area, $\bar{\Phi}_{j}$ is the non-fluctuation component of the potential, and $\Phi_{j}^{\prime}$ is the fluctuation component of the potential. On the other hand, the threshold $\Theta$ is assumed to be determined by the relation between a refuge area and a resident and is expressed as follows:

$\Theta_{i j}=\bar{\Theta}_{i j}+\Theta_{i j}^{\prime}$

where $i$ is the identification mark of a resident, $\bar{\Theta}_{i j}$ is the non-fluctuation component of the threshold, and $\Theta_{i j}^{\prime}$ is the fluctuation component of the threshold. In the model, the non-fluctuation component of the threshold $\bar{\Theta}_{i j}$ is expressed as a liner function of the governing factors obtained from the above discussion:

$\bar{\Theta}_{i j}=\alpha_{1} \cdot t_{i}+\alpha_{2} \cdot s_{i j}+\alpha_{3} \cdot d_{i j}+\alpha_{4}$

where $\alpha_{1}, \alpha_{2}, \alpha_{3}, \alpha_{4}$ are constant, $t$ is the duration of residence (year), $s$ is the direct distance between a refuge area and initial location of a resident (m), and $d$ is the dummy variable whose value is 1 if there is a gap interrupting evacuation between a refuge area and a resident, otherwise 0.

The recognition probability $P_{R}$ is given as follows from Eq. 1:

$P_{R}=\mathrm{P}\left(\Phi_{j} \geq \Theta_{i j}\right)=\mathrm{P}\left(\Theta_{i j}^{\prime}-\Phi_{j}^{\prime} \leq \bar{\Phi}_{j}-\bar{\Theta}_{i j}\right)=F\left(\bar{\Phi}_{j}-\bar{\Theta}_{i j}\right)$

where $\mathrm{P}(A)$ is the probability that event $A$ arises, and $F$ is the cumulative distribution function of $\Theta_{i j}^{\prime}-\Phi_{j}^{\prime}$. In the model, the fluctuation components $\Phi_{j}^{\prime}$ and $\Theta_{i j}^{\prime}$ are assumed to independently vary according to Gumbel distribution. The cumulative distribution function of random variable $X$ according to Gumbel distribution $F(x)$ is expressed as follows:

$F(x)=\exp \left[-\exp \left(-\frac{x-a}{b}\right)\right]$

where $a$ and $b$ are constant. When independent random variables $X_{1}$ and $X_{2}$ are according to Gumbel distribution where $a$ is equal to 0 and $b$ is equal to 1 , the cumulative distribution function of $X_{2}-X_{1}$ is known to be given as follows:

$\mathrm{P}\left(X_{2}-X_{1} \leq x\right)=\frac{1}{1+\exp (-x)}$ 
Thus the recognition probability $P_{R}$ expressed by Eq. 5 is rewritten as follows:

$$
P_{R}=\mathrm{P}\left(\Theta_{i j}^{\prime}-\Phi_{j}^{\prime} \leq \bar{\Phi}_{j}-\bar{\Theta}_{i j}\right)=\frac{1}{1+\exp \left[-\left(\bar{\Phi}_{j}-\bar{\Theta}_{i j}\right)\right]}
$$

\section{Validation of Recognition Model}

The unknown parameters included in Eq. 8 were estimated by using the survey data, i.e., (1) the nonfluctuation components of the potential $\left(\bar{\Phi}_{1}, \bar{\Phi}_{2}, \cdots, \bar{\Phi}_{N}\right)$; and (2) the constants regarding the threshold $\left(\alpha_{1}, \alpha_{2}, \alpha_{3}, \alpha_{4}\right)$. Estimating the parameters, maximum-likelihood method and regression model were used simultaneously. In maximum-likelihood method, unknown parameters are calculated by solving the following equation with Newton method:

$$
\frac{\partial \log L(\boldsymbol{\beta})}{\partial \boldsymbol{\beta}}=0
$$

where $\boldsymbol{\beta}$ is the matrix of unknown parameters, and $L$ is the likelihood function. The function $L$ is defined as the probability that the data observed by the survey arises simultaneously and is expressed as follows:

$$
L=\prod_{i=1}^{M}\left(\prod_{k=1}^{N_{i}}\left(P_{R}\right) \prod_{l=1}^{N_{R}-N_{i}}\left(1-P_{R}\right)\right)
$$

where $i$ is the identification mark of a subject, $M(=2,267)$ is the number of the subjects, $N_{i}$ is the number of the refuge areas recognized as evacuation destination by a subject $i$, and $N_{R}$ is the number of the refuge areas whose potentials are estimated by maximum-likelihood method.

In this analysis, $N_{R}$ was set as 31 refuge areas which were answered correctly by more than 5 subjects. As to the rest of the refuge areas $(=36)$, the non-fluctuation components of the potential were predicted by using the regression model developed based on the estimated results by maximum-likelihood method. The gaps interrupting evacuation were set by the rivers, railways and mountains of more than $40 \mathrm{~m}$ width.

\section{Estimated Results of Potential}

The estimated values of the potential by maximum-likelihood method are shown in Fig. 6, where the refuge areas were classified into five categories: (a) park; (b) school; (c) river; (d) historical space; and (e) other. Note that the potential is relative index so that the value may be either positive or negative. Approximate curves for each category were obtained as follows:

$$
\bar{\Phi}_{j}=\left\{\begin{array}{lll}
-1.107+1.294 \log (S) & (R=0.727) & \cdots \text { Park } \\
-5.466+5.056 \log (S) & (R=0.581) & \cdots \text { School } \\
-0.337+0.614 \log (S) & (R=0.438) & \cdots \text { River } \\
-1.043+1.061 \log (S) & (R=0.785) & \cdots \text { Historical - space } \\
-1.419+0.731 \log (S) & (R=0.911) & \cdots \text { Other }
\end{array}\right.
$$

where $S$ is the site area of a refuge area (ha), and $R$ is the correlation coefficient. As a result, the estimated values of the potential were positively correlated with the site area $S$. However there was poor correlation between both variables for refuge areas categorized in "river". 


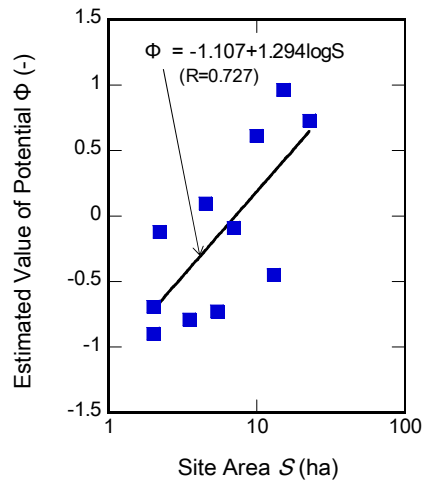

(a)

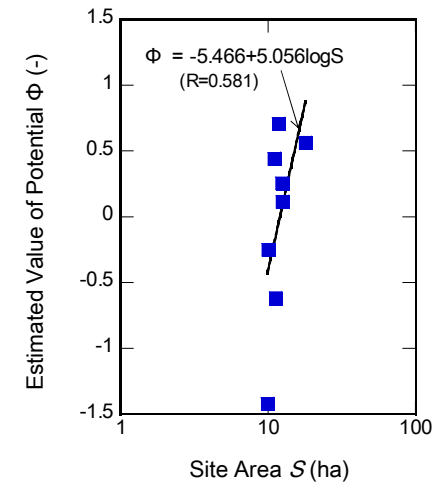

(b)

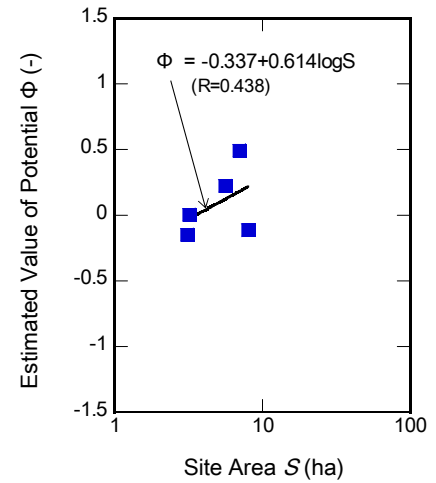

(c)

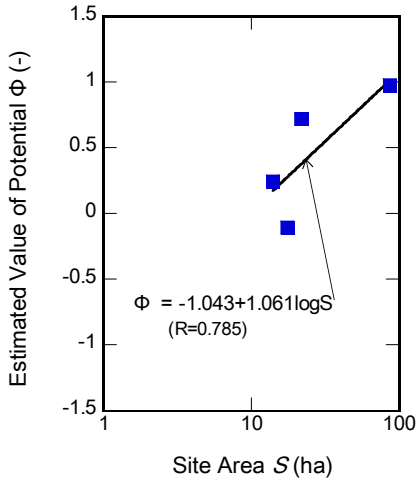

(d)

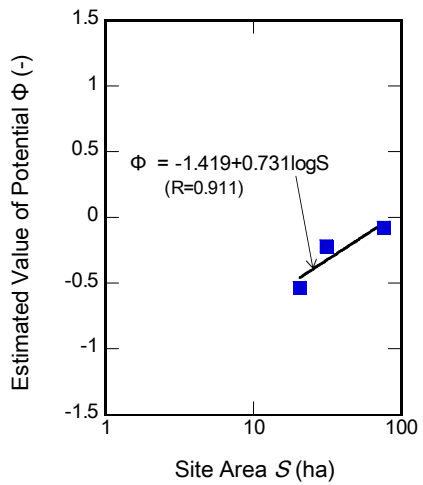

(e)

Fig. 6. Estimated values of potential by maximum-likelihood method: (a) park; (b) school; (c) river; (d) historical space; (e) other.

The estimated values of the potential for all the refuge areas are listed in Table 4, and visualized in Fig. 7. In Fig. 7, the height of the bars corresponds to the estimated values of the potential. The potential was estimated to be the highest for Imperial Palace Park of Kyoto, followed by Nisikyogoku Atheltic Park, Takaragaike Park, Umekoji Park, Nijo Castle and Kyoto University Ground. Especially the values of the potential of Imperial Palace Park of Kyoto and Nijo Castle are high because they are the important touristic/cultural symbols of Kyoto City. Such high-potential refuge areas concentrate in the central area of Kyoto as shown in Fig. 7. So in post-earthquake fire, many residents in this area may recognize evacuation destination at high probability. However, it is concerned that a large number of evacuees may concentrate on a single refuge area depending on fire spread condition. Thus, the refuge area may not be able to accommodate all of the evacuees. On the other hand, in the western area where high-potential refuge areas are rare, many residents may wander around in urban area without recognizing evacuation destination. So it will be required that some organizations such as firefighters and police officers guide the residents to neighboring refuge areas in post-earthquake fire situation. 


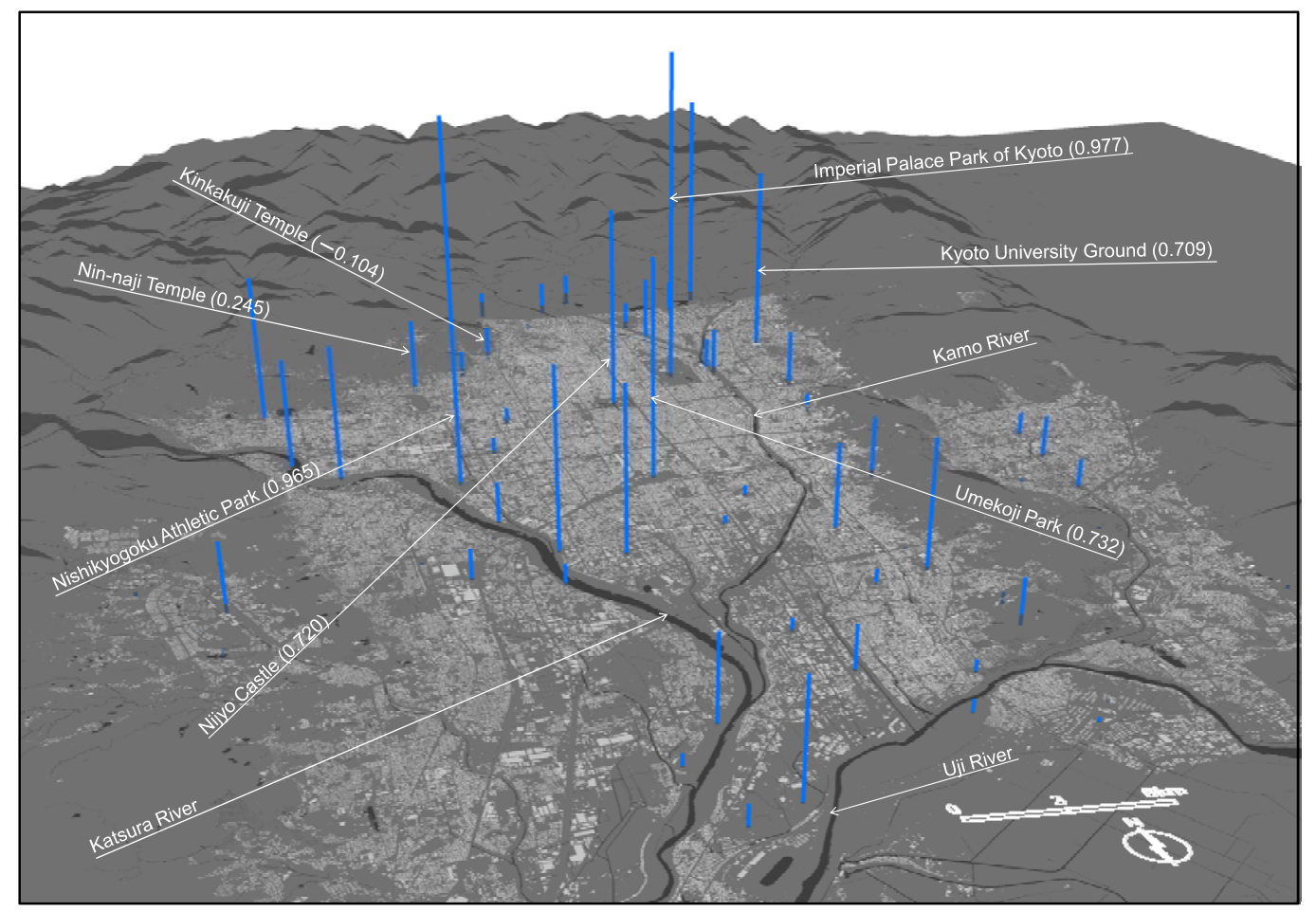

Fig. 7. Spatial distribution of estimated values of potential of refuge areas in Kyoto City.

Table 4. List of estimated values of potential of refuge areas in Kyoto City.

\begin{tabular}{|l|c|r|r|}
\hline Name of post-earthquake fire refuge area & Class & Site area (ha) & $\begin{array}{c}\text { Estimated value } \\
\text { of potential (-) }\end{array}$ \\
\hline Imperial palace park of Kyoto & historical & 87.0 & 0.9772 \\
\hline Nisikyogoku athletic park & park & 15.0 & 0.9652 \\
\hline Takaragaike park & park & 30.0 & 0.8044 \\
\hline Umekoji park & park & 22.7 & 0.7324 \\
\hline Nijo castle & historical & 21.8 & 0.7196 \\
\hline Kyoto university ground & school & 11.8 & 0.7085 \\
\hline Kisyoin park & park & 9.9 & 0.6137 \\
\hline Tonan high school ground & school & 1.4 & 0.5731 \\
\hline Bukkyo university ground & school & 18.0 & 0.5637 \\
\hline Left-bank of Katura river (middle part) & river & 7.0 & 0.4936 \\
\hline Kyoto university of education & school & 11.0 & 0.4436 \\
\hline Right-bank of Katura river (upper part) & river & 15.5 & 0.3939 \\
\hline Yokooji athletic park & park & 13.0 & 0.3344 \\
\hline Kyoto police school ground & school & 12.4 & 0.2527 \\
\hline Ninnaji temple & historical & 14.0 & 0.2454 \\
\hline Right-bank of Kamo river (middle part) & river & 5.6 & 0.2224 \\
\hline Hadukasi athletic park & park & 10.4 & 0.2090 \\
\hline Obatagawa central park & park & 9.0 & 0.1278 \\
\hline Hiyosigaoka high school ground & school & 12.5 & 0.1132 \\
\hline Okazaki park & park & 4.5 & 0.0972 \\
\hline Left-bank of Kamo river (lower part) & river & 3.2 & 0.0060 \\
\hline Higasino park & park & 6.3 & -0.0727 \\
\hline Momoyama imperial mausoleum & other & 76.0 & -0.0788 \\
\hline Takaragaike sports space & park & 7.0 & -0.0908 \\
\hline
\end{tabular}


Table 4 (continued). List of estimated values of potential of refuge areas in Kyoto City.

\begin{tabular}{|c|c|c|c|}
\hline Name of post-earthquake fire refuge area & Class & Site area (ha) & $\begin{array}{r}\text { Estimated value } \\
\text { of potential (-) }\end{array}$ \\
\hline Kinkakuji temple & historical & 17.5 & -0.1036 \\
\hline Left-bank of Katura river (lower part) & river & 8.0 & -0.1144 \\
\hline Right-bank of Kamo river (upper part) & river & 2.3 & -0.1208 \\
\hline Misu park & park & 2.2 & -0.1208 \\
\hline Golf cource of Kyoto-Kamigamo & other & 55.6 & -0.1434 \\
\hline Right-bank of Kamo river (lower part) & river & 3.1 & -0.1489 \\
\hline Kyoto botanical garden & other & 31.2 & -0.2179 \\
\hline Golf cource of Kyoto-Nisikamo & other & 40.0 & -0.2479 \\
\hline Ritumeikan university ground & school & 10.0 & -0.2486 \\
\hline Katura garrison & other & 37.4 & -0.2692 \\
\hline Kansyuji park & park & 4.4 & -0.2744 \\
\hline Yamasina central park & park & 4.0 & -0.3279 \\
\hline Maruyama park & park & 13.0 & -0.4497 \\
\hline Kuzebasi western park & park & 3.1 & -0.4712 \\
\hline Kyoto racetrack & other & 18.0 & -0.5014 \\
\hline Shimadzu corporation ground & other & 20.5 & -0.5337 \\
\hline Saiin park & park & 2.6 & -0.5700 \\
\hline Fire academy ground & school & 11.3 & -0.6150 \\
\hline Husimi park & park & 2.0 & -0.6894 \\
\hline Mukaijima-south elementary school ground & school & 8.7 & -0.7158 \\
\hline Simotoba park & park & 2.0 & -0.7175 \\
\hline Kyoto driving license examination ground & other & 8.9 & -0.7250 \\
\hline Husimi-Kitahori park & park & 5.4 & -0.7276 \\
\hline Tonoda park & park & 3.5 & -0.7872 \\
\hline Kamitoba park & park & 1.7 & -0.8088 \\
\hline Omiya traffic park & park & 2.0 & -0.8977 \\
\hline Takenosato elementary school ground & school & 7.3 & -1.1010 \\
\hline Kyoto city university of arts & school & 7.2 & -1.1313 \\
\hline Mukaijima junior high school ground & school & 7.0 & -1.1932 \\
\hline Rakuto driving school & other & 1.7 & -1.2505 \\
\hline Hino outdoor center & other & 1.6 & -1.2698 \\
\hline Hukakusa junior high school ground & school & 9.9 & -1.4231 \\
\hline Ryukoku university ground & school & 6.0 & -1.5317 \\
\hline Rakusei junior high school ground & school & 6.0 & -1.5317 \\
\hline Katurasaka elementary school ground & school & 5.9 & -1.5686 \\
\hline Katura high school ground & school & 5.4 & -1.7630 \\
\hline Mukaijima-Hujinoki elementary school ground & school & 5.0 & -1.9320 \\
\hline Katuragawa junior high school ground & school & 4.8 & -2.0216 \\
\hline Ogurisu junior high school ground & school & 3.5 & -2.7152 \\
\hline Rituryo junior high school ground & school & 3.2 & -2.9120 \\
\hline Kasugaoka junior high school ground & school & 3.2 & -2.9120 \\
\hline Higasiyama high school ground & school & 3.0 & -3.0537 \\
\hline Rakusei junior high school ground & school & 1.5 & -4.5757 \\
\hline
\end{tabular}




\section{Estimated Results of Threshold}

The constants regarding the threshold $\left(\alpha_{1}, \alpha_{2}, \alpha_{3}, \alpha_{4}\right)$ were estimated as follows:

$$
\begin{aligned}
& \alpha_{1}=-5.851 \times 10^{-3} \\
& \alpha_{2}=2.325 \times 10^{-3} \\
& \alpha_{3}=0.717 \\
& \alpha_{4}=-0.132
\end{aligned}
$$

The constant regarding the duration of residence $\alpha_{1}$ was estimated to be negative. This implies that the longer the living time in urban area, the lower the threshold $\Theta$ (the higher the recognition probability $P_{R}$ ). The constant regarding the direct distance between a refuge area and initial location of a resident $\alpha_{2}$ was estimated to be positive, i.e., increase of the distance $s$ elevates the threshold $\Theta$ (reduces the recognition probability $P_{R}$ ). The constant regarding the gap interrupting evacuation $\alpha_{3}$ was estimated to be positive, so the gap is thought to induce some psychological resistance and affect the choice of the refuge area.

\section{CONCLUSION}

In this study, recognition degree of refuge areas by Kyoto City residents in post-earthquake fire situation was modeled by introducing new concepts: potential of a refuge area $\Phi$ and threshold of a resident $\Theta$, which are the hypothetical quantities to mathematically formulate the decision structure of evacuation destination. Firstly, the interview survey was carried out on 2,267 residents in Kyoto City, and the following factors were identified as the governing factors of recognition degree of refuge areas: (1) duration of residence; (2) direct distance between a refuge area and a resident; and (3) geographical gap interrupting evacuation. Then, recognition degree of refuge areas was formulated considering the factors and the model was validated by using the survey data.

The potential $\Phi$ and the threshold $\Theta$ could be quantified though sufficient validation of the values is difficult, so that it became possible to predict evacuation destination of a resident considering bias of recognition degree of refuge areas by using the parameters estimated in this paper. Following this study, the present model for city evacuation [1-2] will be refined by incorporating the recognition model developed in this paper. It is expected that the refined model will be able to predict the evacuation behavior more reasonably and become an effective tool for evaluation of evacuation safety measures.

\section{REFERENCES}

[1] Nishino, T., Tsuburaya, S., Himoto, K. and Tanaka, T., 2009. A Study on the Estimation of the Evacuation Behaviors of Tokyo City Residents in the Kanto Earthquake Fire. Fire Safety Science 9: 453-464. http://dx.doi.org/10.3801/IAFSS.FSS.9-453

[2] Nishino, T., Tsuburaya, S., Himoto, K. and Tanaka, T., "Validation of the Potential-based Evacuation Model of City Residents in Post-earthquake Fire," Proceedings of $5^{\text {th }}$ International Conference on Pedestrian and Evacuation Dynamics, 2010, pp.399-406.

[3] "Development of Prevention Method for Urban Fire," Ministry of Land, Infrastructure and Transport, 1982, pp.137-154. (in Japanese)

[4] Koide, K. and Moriwaki, T., (1982) A Investigation of Inhabitant's Consciousness in Reference to Refuge from Infrequent Earthquake Fires, Transactions of the Architectural Institute of Japan 315: 171-178. (in Japanese)

[5] "Regional Disaster Prevention Plan of Kyoto City," Kyoto Conference on Disaster Reduction, 2010. (in Japanese) 